\title{
Severe aortic stenosis without left ventricular hypertrophy: prevalence, predictors, and short- term follow up after aortic valve replacement
}

\author{
Christian Seiler, Rolf Jenni
}

\begin{abstract}
Objectives-The purpose of the present study in patients with severe aortic stenosis was to assess the prevalence of absent left ventricular hypertrophy (LVH)(determined according to mass criteria), to identify predictors of absent $\mathrm{LVH}$, and to assess short-term left ventricular adaptation and prognosis after aortic valve replacement.
\end{abstract}

Methods-Left ventricular mass (LVM) was determined by echocardiography in 109 men and 101 women with severe aortic stenosis (mean pressure gradient $\leqslant 50 \mathrm{~mm} \mathrm{Hg}$ ). LVH was defined as LVM $\geqslant 109 \mathrm{~g} / \mathrm{m}^{2}$ in women and LVM $\geqslant 134 \mathrm{~g} / \mathrm{m}^{2}$ in men.

Results-One hundred and eighty nine patients showed LVH (group 1) $(90 \%$; mean (SD) age 65 (14) years), and 21 showed no LVH (group 2) (10\%, age 57 (21) years $P=0.02$ for difference in age). Twelve $(6 \%)$ of those without LVH had increased relative wall thickness (that is, $\geqslant 0.45$ with $\mathrm{LV}$ concentric remodelling) and nine (4\%) showed no macroscopically detectable hypertrophic adaptation. The following variables were associated with the absence of LVH: low body surface area, low body mass index, and increased cardiac index. $76 / 210$ patients were followed up a mean of six months after aortic valve replacement. The frequency of adequate ventricular adaptation to the decreased afterload after aortic valve replacement was higher in patients with LVH than in those without. Mortality six months after aortic valve repacement was lower, but not significantly, in patients with LVH $(7 \cdot 6 \%)$ than in those without LVH $(12 \cdot 5 \%, P=0 \cdot 10)$.

Conclusions-A tenth of patients with severe aortic stenosis did not develop LVH according to mass criteria; $4 \%$ of the patients did not have any macroscopic signs of myocardial adaptation to the pressure overload despite longstanding disease. Small body size was independently associated with lack of LVH according to mass criteria. Six months after aortic valve replacement, ventricular adaptation was more often adequate in patients with LVH than in those without.

(Heart 1996;76:250-255)

Keywords: valvular heart disease; aortic stenosis; hypertrophy; gender
Left ventricular hypertrophy is crucial to the adaptation of the systemic circulation to pressure or volume overload. ${ }^{1}$ In severe aortic stenosis the detection of extreme left ventricular hypertrophy indicates a poor prognosis. ${ }^{2}$ On the other hand, there are reports that some patients show no or only a slight hypertrophic response to the severe long-term increase in afterload. ${ }^{3-5}$ Both excessive and minimal or no hypertrophic responses to severe aortic stenosis have been shown to be related to increased perioperative and postoperative mortality after aortic valve replacement. ${ }^{6-8}$ When hypertrophy is excessive, systolic dysfunction increases mortality. ${ }^{6}$ It has been suggested that increased left ventricular hypertrophy associated with increased vascular resistance in the coronary microvasculature may contribute to subendocardial ischaemia and lead to ventricular dysfunction. ${ }^{9}$ The mechanism relating minimal or no hypertrophy in severe aortic stenosis to increased postoperative mortality has not been elucidated. ${ }^{78}$ Moreover, the frequency of and factors associated with an absence of the hypertrophic response to severe aortic stenosis are not known. An association of female gender with small, hypercontractile left ventricles showing increased relative wall thickness has been suggested. ${ }^{4}$

Thus the purpose of the present, retrospective study in patients with severe aortic stenosis was (a) to determine the prevalence of absent left ventricular hypertrophy according to mass criteria, $(b)$ to identify factors associated with the lack of left ventricular hypertrophy, and $(c)$ to assess ventricular adaptation to the decreased afterload and the outcome six months after aortic valve replacement in patients with and without left ventricular hypertrophy.

\section{Patients and methods}

STUDY POPULATION

From 1989 to 1992 all echocardiographic studies performed at the University Hospital of Zurich (about 16000) were reviewed to identify patients fulfilling the following criteria: (1) severe aortic stenosis with a mean pressure gradient across the aortic valve of $\geqslant 50 \mathrm{~mm} \mathrm{Hg}$, (2) no more than mild aortic regurgitation, (3) no clinical signs of coronary artery disease, and (4) no more than mild mitral regurgitation. In 194 patients the aortic valve area was calculated using the continuity equation; it was $0.67 \quad(0.22) \mathrm{cm}^{2}$. Eight patients fulfilling these criteria were excluded because of poor quality $M$ mode echocardio- 


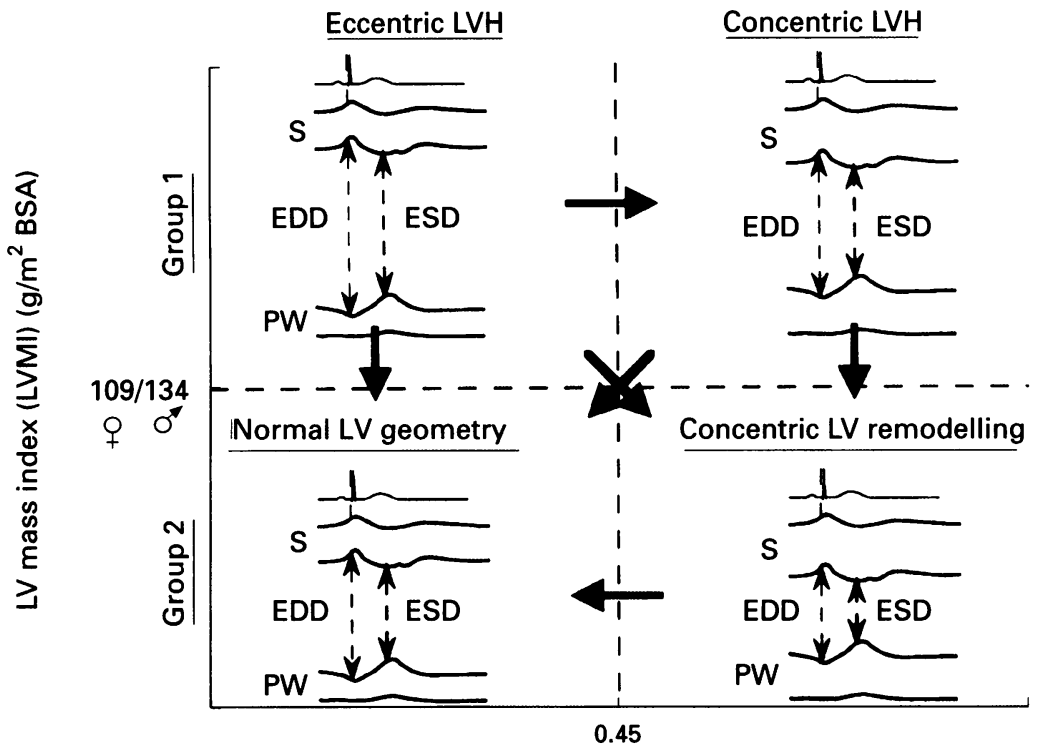

Relative LV wall thickness

\begin{tabular}{|l|}
$\longrightarrow$ \\
mass and relative wall \\
thickness after AVR \\
indicating adequate adaptation of \\
LV geometry in response to \\
decreased wall stress
\end{tabular}

Figure $1 \quad L V$ mass and relative wall thickness. Schematic $M$ mode echocardiograms of different forms of $L V$ geometry are shown for the combined values of $L V$ mass index (MI) (y axis; calculated on the basis of echocardiographic measurements by the ellipsoid formula of Troy et al ${ }^{12}$ ) and relative $L V$ wall thickness $(T h)\left(x\right.$ axis; Th $\left.=2 P W \div E D D^{\prime 8}\right)$. The broken lines indicate the limit between normal and increased LVMI and Th, respectively. ${ }^{1318}$ Arrows indicate the direction of adequate adaptation of $L V$ geometry in response to the decreased afterload after aortic valve replacement. $B S A$, body surface area in $m^{2} ; E D D$, end diastolic diameter; $E S D$, end systolic diameter; $L V H$, left ventricular hypertrophy; $P W$, posterior wall; $S$, septal wall.

graphic images. Two hundred and ten patients (109 men and 101 women) were finally included in the study. Information on clinical status of these patients was obtained by reviewing their charts.

DOPPLER ECHOCARDIOGRAPHIC RECORDING Doppler echocardiographic recordings were performed using a real time phased array sector scanner (Sonos 500, Hewlett Packard, Andover, Massachusetts, USA) with integrated colour Doppler facilities and a transducer containing a $2.5 \mathrm{MHz}$ crystal set for imaging and continuous wave (CW) Doppler. The recordings were stored together with a trace from the peripheral lead of the electro-

Table 1 Demographic data

\begin{tabular}{llll}
\hline & LVH & No LVH & $P$ \\
\hline Number & 189 & 21 & \\
Age (yr) & $65(14)$ & $57(21)$ & $0 \cdot 02$ \\
Female/male (\% female) & $96 / 93(51)$ & $6 / 15(29)$ & $\mathrm{NS}$ \\
Body surface area $\left(\mathrm{BSA}, \mathrm{m}^{2}\right)$ & $1 \cdot 88(0 \cdot 28)$ & $1 \cdot 72(0 \cdot 23)$ & $0 \cdot 007$ \\
Body mass index $\left(\mathrm{BMI}, \mathrm{kg} / \mathrm{m}^{2}\right)$ & $25(3)$ & $24(3)$ & $0 \cdot 047$ \\
Obese (BMI > 30 kg/m²) & $17 / 185(9 \%)$ & $0 / 25$ & $0 \cdot 12$ \\
Heart rate & $76(16)$ & $78(11)$ & $\mathrm{NS}$ \\
Sinus rhythm $(\%)$ & $164 / 189(87)$ & $18 / 21(84)$ & $\mathrm{NS}$ \\
Atrial fibrillation $(\%)$ & $25 / 189(13)$ & $3 / 21(16)$ & $\mathrm{NS}$ \\
Aortic valve area $\left(\mathrm{cm}^{2}\right)(\mathrm{n}=194)^{\star}$ & $0 \cdot 64(0 \cdot 22)$ & $0 \cdot 69(0 \cdot 28)$ & $\mathrm{NS}$ \\
& $(\mathrm{n}=173)$ & $(\mathrm{n}=21)$ & $\mathrm{NS}$ \\
Aortic valve area index $\left(\mathrm{cm}^{2} / \mathrm{BSA}\right)$ & $0 \cdot 34(0 \cdot 15)$ & $0 \cdot 40(0 \cdot 16)$ & $\mathrm{NS}$ \\
Mean transaortic gradient $(\mathrm{mm} \mathrm{Hg})$ & $67(13)$ & $65(11)$ & $\mathrm{NS}$
\end{tabular}

LVH, left ventricular hypertrophy (defined as a left ventricular mass for women of $\geqslant 109 \mathrm{~g} / \mathrm{m}^{2}$ BSA and for men as LVM $\geqslant 134 \mathrm{~g} / \mathrm{m}^{2} \mathrm{BSA}^{13}$ ).

*Valve area calculated by the continuity equation. cardiogram (ECG) on VHS video tape and were analysed off-line using a track ball system. To minimise the effect of respiratory variations on the assessment of dimensions and velocity spectra, the data reported are the mean of at least three beats. Doppler echocardiographic data were evaluated by two independent observers who performed all measurements after the end of the study.

Serial, cross sectionally guided $\mathbf{M}$ mode recordings were made by standard techniques with the subject in a supine left oblique position. ${ }^{10}$

ECHOCARDIOGRAPHIC MEASUREMENTS

Left ventricular (LV) measurements were obtained at end systole and at end diastole. End diastolic measurements were made according to the American Society of Echocardiography (ASE) convention (that is, the leading edge method ${ }^{11}$ ). The LV measurements included interventricular septal thickness at end diastole (S), the posterior wall thickness at end diastole (PW), and the LV internal dimension at end systole (ESD) and at end diastole (EDD) (fig 1). From the diastolic measurements, left ventricular mass (LVM) was calculated from the ASE-convention measurements according to the equation of Troy et $a l^{12}:$ LVM $(\mathrm{g})=1.04\{(\mathrm{EDD}+\mathrm{S}+$ $\left.P W)^{3}-(E D D)^{3}\right\}$. This estimate of LVM has been shown to correlate strongly with LVM derived from the Penn conventions (that is, the trailing edge method ${ }^{13}$ ). Accordingly, LVM-Penn values (subsequently referred to as LVM) were calculated with the following regression equations:

$$
\begin{gathered}
\text { LVM-Penn (males) }=0.93 \text { (LVM-ASE) } \\
-17.92 \mathrm{~g} ; \text { LVM-Penn (females) }= \\
0.88 \text { (LVM-ASE) }-9 \mathrm{~g}
\end{gathered}
$$

LVM-Penn measurements have been shown to correlate strongly with necropsy and angiographic data on LVM. ${ }^{14-17}$ Left ventricular mass index (LVMI) was calculated by dividing LVM by body surface area (BSA, $\mathrm{m}^{2}$ ).

Criteria for left ventricular hypertrophy (LVH) according to LVMI were LVMI $\geqslant 134$ $\mathrm{g} / \mathrm{m}^{2}$ for men and LVMI $\geqslant 109 \mathrm{~g} / \mathrm{m}^{2}$ for women, representing the sex-specific 97 th percentile of a widely used reference standard in a general population sample ${ }^{13}$ (fig 1). The entire study population was divided into two groups according to their LVMI: patients with LVH (group 1) and patients without LVH (group 2 ). We analysed the prevalence of absent LVH determined by mass criteria and the demographic, clinical, echocardiographic, and haemodynamic factors associated with it.

In patients without $\mathrm{LVH}$ we determined the prevalence of an increase in relative $\mathrm{LV}$ wall thickness $\left(2 P W \div\right.$ EDD $\geqslant 0.45^{18}$; that is, left ventricular concentric remodelling, $\mathrm{LVCR}^{5}$ ), normal relative $L V$ wall thickness, and predictors of the presence or absence of LVCR (fig 1).

FOLLOW-UP

From January 1989 through July 1994, a total 
Table 2 Clinical data

\begin{tabular}{llll}
\hline & $L V H$ & No LVH & $P$ \\
\hline Years since diagnosis & $7 \cdot 6(7 \cdot 1)$ & $5 \cdot 2 \pm 4 \cdot 0$ & NS \\
NYHA class & $2 \cdot 3(0 \cdot 5)$ & $2 \cdot 0(0 \cdot 5)$ & NS \\
Angina pectoris (\%) & $115 / 189(64)$ & $7 / 21(33)$ & NS \\
Dizziness (\%) & $74 / 189(39)$ & $7 / 21(33)$ & NS \\
Syncope (\%) & $40 / 189(21)$ & $6 / 21(28)$ & NS \\
Pulmonary venous congestion on x ray (\%) & $41 / 189(22)$ & $0 / 21(0)$ & $0 \cdot 19$ \\
History of hypertension (\%) & $44 / 189(23)$ & $3 / 21(16)$ & NS \\
Ergometric working capacity & $63(18)$ & $90(26)$ & $0 \cdot 03$ \\
$\quad$ (in \% of required workload) & $4 \cdot 2(1 \cdot 6)$ & $2 \cdot 6(0 \cdot 7)$ & $0 \cdot 03$ \\
\hline Sokolow index (mV) & &
\end{tabular}

$\mathrm{LVH}$, left ventricular hypertrophy (defined as a left ventricular mass for women of $\geqslant 109 \mathrm{~g} / \mathrm{m}^{2}$ BSA and for men as LVM $\left.\geqslant 134 \mathrm{~g} / \mathrm{m}^{2} \mathrm{BSA}^{13}\right)$.

$\star$ Valve area calculated by the continuity equation.

Table 3 Echocardiographic data (mean (SD))

\begin{tabular}{lccl}
\hline Variable & LVH & No LVH & $P$ \\
\hline LV end diastolic diameter (cm) & $5 \cdot 1(0 \cdot 7)$ & $4 \cdot 3(0 \cdot 5)$ & $0 \cdot 0001$ \\
LV end systolic diameter (cm) & $3 \cdot 3(0 \cdot 8)$ & $2 \cdot 4(0 \cdot 6)$ & $0 \cdot 0001$ \\
LV end diastolic diameter index (cm/BSA) & $2 \cdot 9(0 \cdot 4)$ & $2 \cdot 5(0 \cdot 3)$ & $0 \cdot 0001$ \\
LV end systolic diameter index (cm/BSA) & $1 \cdot 8(0 \cdot 5)$ & $1 \cdot 5(0 \cdot 3)$ & $0 \cdot 0002$ \\
LV fractional shortening (\%) & $37(10)$ & $44(10)$ & $0 \cdot 002$ \\
LV posterior wall thickness (cm) & $1 \cdot 27(0 \cdot 18)$ & $1 \cdot 14(0 \cdot 17)$ & $0 \cdot 0006$ \\
LV septal wall thickness (cm) & $1 \cdot 57(0 \cdot 36)$ & $1 \cdot 31(0 \cdot 21)$ & $0 \cdot 0007$ \\
Mean transaortic gradient (mm Hg) & $67(13)$ & $65(11)$ & NS \\
Subvalvular gradient (mm Hg) & $1 \cdot 1(3 \cdot 3)$ & $2 \cdot 4(5 \cdot 3)$ & $0 \cdot 06$ \\
Left atrial dimension (cm) & $4 \cdot 2(0 \cdot 8)$ & $3 \cdot 8(0 \cdot 7)$ & $0 \cdot 01$ \\
Bicuspid, non-calcified valves & $4 / 185(2 \%)$ & $3 / 25(12 \%)$ & $0 \cdot 04$ \\
Relative wall thickness (2PW $\div$ EDD) & $0 \cdot 51(0 \cdot 11)$ & $0 \cdot 60(0 \cdot 09)$ & $0 \cdot 05$ \\
LV mass (g) & $314(94)$ & $193(42)$ & $0 \cdot 0001$ \\
LV mass index (g/BSA) & $167(43)$ & $112(16)$ & $0 \cdot 0001$ \\
\hline
\end{tabular}

$\mathrm{LVH}$, left ventricular hypertrophy (defined as a left ventricular mass for women of $\geqslant 109 \mathrm{~g} / \mathrm{m}^{2}$ $\mathrm{BSA}$ and for men as LVM $\left.\geqslant 134 \mathrm{~g} / \mathrm{m}^{2} \mathrm{BSA}^{13}\right)$.

$\star$ Valve area calculated by the continuity equation.

of 74 patients (age 62 (11) years; 40 men, 34 women) underwent aortic valve replacement (AVR) because of worsening symptoms. They had a follow up echocardiogram $5.6(3.0)$ months (from $0 \cdot 2$ to $29 \cdot 2$ months) after AVR. Changes in mean pressure gradients across the aortic valve, LVMI, fractional shortening, relative wall thickness, and LV geometry were noted. Echocardiographic variables at baseline that were predictive of a change in LV geometry that was consistent (or inconsistent) with the reduced afterload after AVR were determined (fig 1).

\section{STATISTICAL ANALYSIS}

Univariate analysis: Between-group comparisons of demographic, clinical, and echocardiographic variables were performed using an unpaired two-sided $t$ test or one-way Anova for continuous variables and a chi-squared test for categorical variables. Regression analysis was used to determine whether there was a correlation between certain continuous variables and LVM. Multivariate analysis: A multiple stepwise regression analysis was used to determine independent predictors of absent LVH in severe aortic stenosis (AS). Only variables not directly or indirectly related to the calculation of LVM that were found to be associated with absent LVH in severe AS in the univariate analysis at a significance level of $<0.05$ were included in the multivariate analysis.

Follow up data were analysed by a paired $t$ test and Anova for repeated measures.

\section{Results}

(A) INITIAL RESULTS

Patient characteristics: tables 1 and 2

There was no statistical difference in the sever-
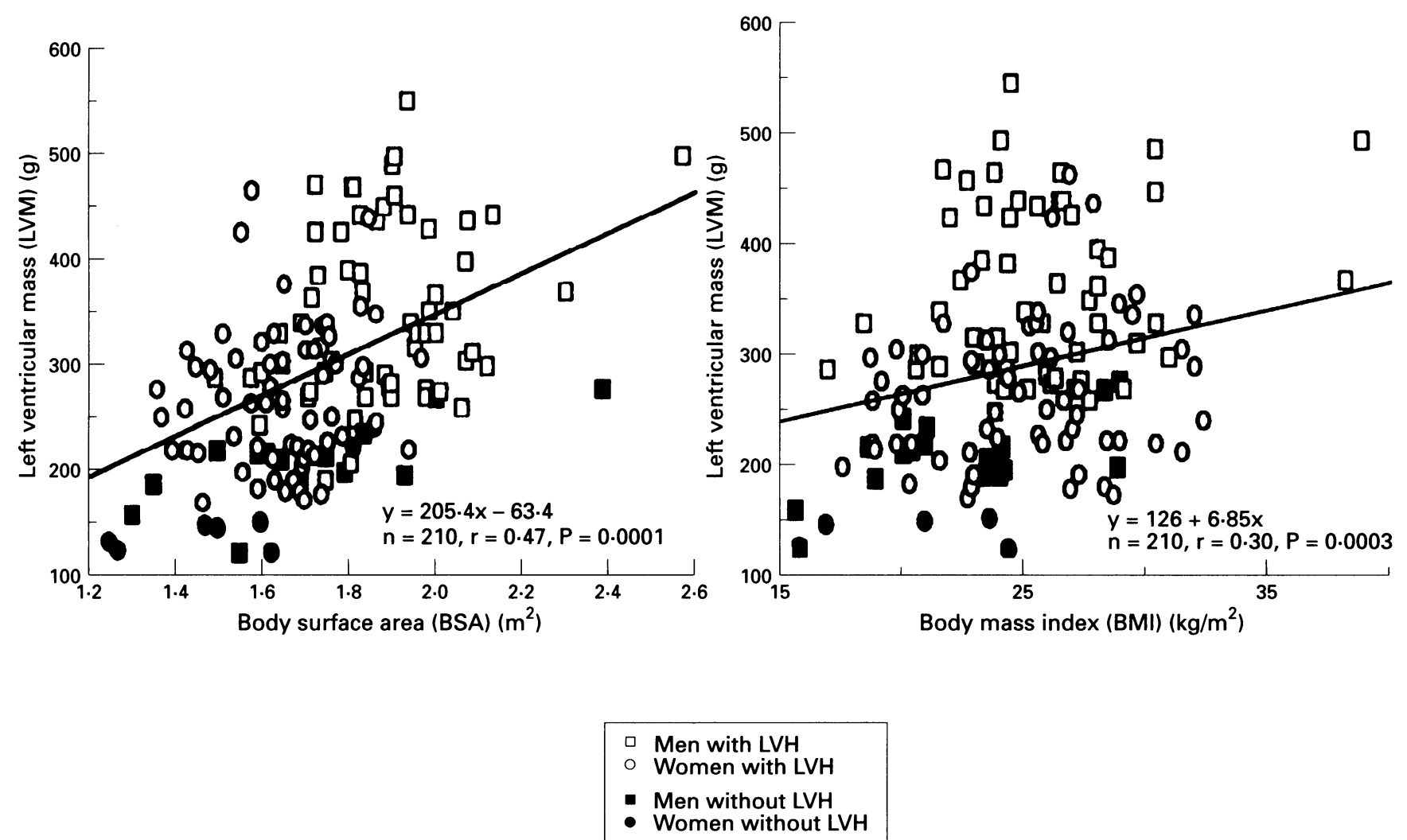

Figure 2(A) There is a significant correlation between body surface area and left ventricular mass. Patients without $L V H$ according to mass criteria tended to have a low BSA regardless of their gender. (B) There is a significant correlation between body mass index and left ventricular mass. All except three patients in the group without LVH according to mass criteria have body mass indices below $25 \mathrm{~kg} / \mathrm{m}^{2}$ and there were no obese patients (BMI $\geqslant 30 \mathrm{~kg} / \mathrm{m}^{2}$ ) in the group without LVH. 
Figure 3 Changes of $L V$ mass index, relative $L V$ wall thickness, and systolic fractional shortening after aortic valve replacement (six month follow up in 74 patients). At baseline examination $L V$ mass index was significantly higher and LV wall thickness and systolic fractional shortening were significantly lower in group 1 left ventricular hypertrophy according to mass criteria) than in group 2 (no left ventricular hypertrophy according to mass criteria), respectively. During follow up, LV mass index decreased significantly in group 1 and $L V$ wall thickness and systolic fractional shortening decreased significantly in group 2 $F U$, follow $u p ; L V$, left ventricular.
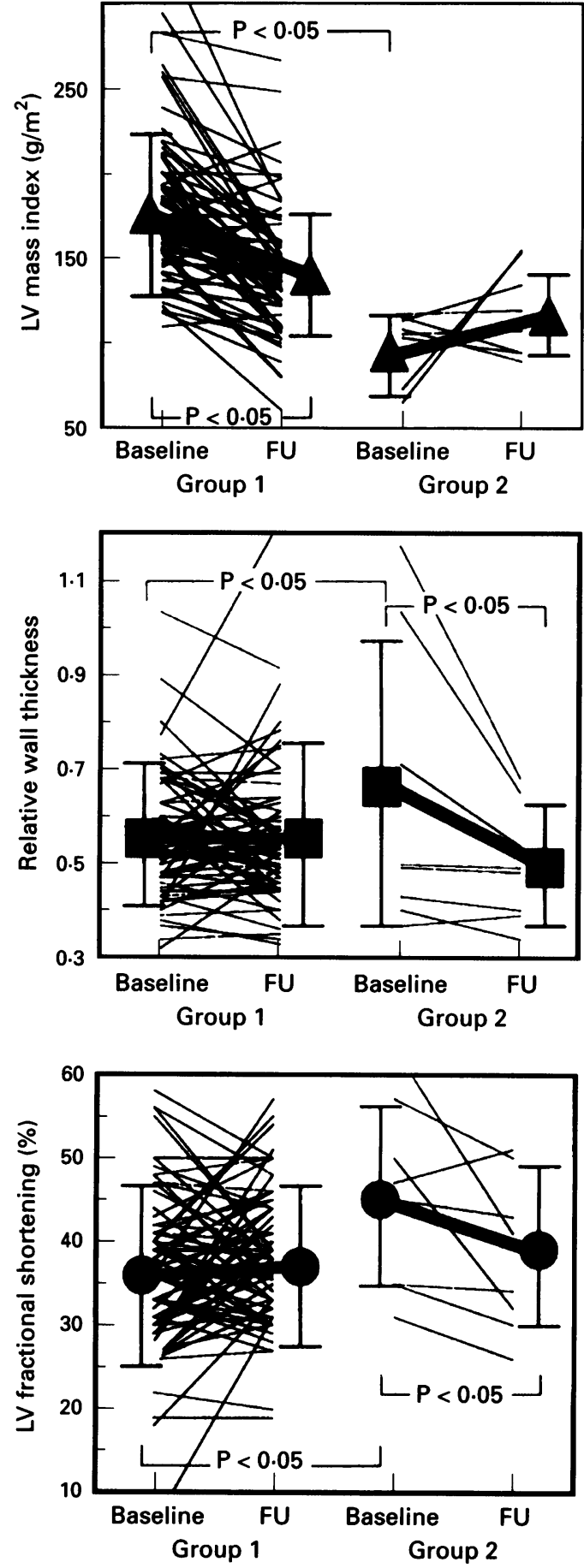

ity of AS as estimated from the mean transaortic gradient across the aortic valve and by the aortic valve area $(n=194)$ between the patients with $\mathrm{LVH}$ and those without (table 1). Hundred and eighty nine of 210 patients with severe AS showed LVH according to mass criteria (group 1,90\%) whereas 21 of 210 patients did not (group 2, 10\%). Patients in group 1 were older than those in group 2: 65 (14) years $v 57$ (21) years $(P=0.02)$. Among patients with LVH there were 96 men and 93 women ( $50 v 50 \%$, NS), and in the group without LVH there was a tendency to a higher proportion of men than women (15/21 $=71 \%$ \% $6 / 21=29 \%$, NS). The following demographic and clinical variables were different in the two groups (tables 1 and 2): body surface area, body mass index (calculated as body weight in kilograms divided by (body height in metres) ${ }^{2}$ ), and ergometric working capacity. There was no statistical difference in the frequency of a history of hypertension or of coronary artery disease between the two groups. The Sokolow-Lyon index for LVH was significantly higher in the group with $\mathrm{LVH}$ than in the group without.

\section{Echocardiographic data: table 3}

Left ventricular end systolic and end diastolic internal dimensions were significantly larger and systolic fractional shortening was smaller in the group with LVH than in the group without. Also septal and posterior wall thickness was higher in the group with LVH than in the group without. Because all these variables are related to the calculation of LVM they represent dependent variables with regard to LVH. In addition the left atrial dimension was larger and bicuspid, non-calcified aortic valves less common in the group with LVH than in the group without.

Relative LV wall thickness, a measure of concentric hypertrophy in patients with LVH and for concentric remodelling (LVCR) in patients without $\mathrm{LVH}$, was smaller in individuals with LVH than in those without.

\section{Multivariate analysis}

Age, body surface area, cardiac index, and the size of the left atrium were independently associated with presence or absence of LVH according to mass criteria in severe AS. Figure 2 shows a significant correlation between body surface area (BSA) and LVM; most patients without LVH had values of BSA below $1.8 \mathrm{~m}^{2}$. Furthermore, body mass index (BMI) was significantly higher in the group with LVH than in the group without (table 1).

\section{Subgroup analysis of patients without $L V H$} according to mass criteria

Among patients without LVH 12/21 (57\%) showed LV concentric remodelling (LVCR) (relative wall thickness $\geqslant 0.45$ ) and 9/21 (43\%) did not. Patients without LVCR were younger than those with LVH and those with LVCR (52 (23) $v 65$ (14) and 64 (19) years, respectively, $P<0.05)$. The interval since diagnosis of aortic stenosis was $3 \cdot 2(6 \cdot 2)$ years in patients without LVCR and $8 \cdot 2(6 \cdot 1)$ years in patients with LVCR $(P<0.05)$.

\section{(B) FOLLOW UP DATA}

Patients with follow up after AVR did not differ from the entire study group with regard to the prevalence of absent LVH or demographic, clinical, and haemodynamic baseline variables. Of the 74 patients in the follow up group, six $(8.1 \%)$ died postoperatively (one of them perioperatively), $5 / 66(7 \cdot 6 \%)$ had LVH according to mass criteria and $1 / 8(12.5 \%)$ did not $(P=$ $0 \cdot 10)$. Individuals in the groups with and without LVH were followed for 5.3 (4.8) and 5.9 (1.1) months after AVR, respectively (NS). Figure 3 shows the changes during follow up after AVR in LVMI, relative wall thickness, and systolic fractional shortening in the groups with and without LVH. Changes in LV geometry (combined changes in LV mass and rela- 
tive wall thickness) during follow up were either consistent or inconsistent with the decreased afterload after AVR (fig 1); patients with LVH were significantly more likely to show appropriate changes in LV geometry (36\% v 0\%, P < 0.05) than those without and significantly more likely to show fewer inappropriate changes $(2 \%$ v $43 \%, \mathrm{P}<0.05)$. Predictors at baseline examination for inconsistent changes in LV geometry after AVR were an increased relative wall thickness and increased mean transaortic pressure gradient.

\section{Discussion}

This study showed that left ventricular (LV) hypertrophic adaptation to aortic stenosis differs widely with body size and age. This adaptive variability is reflected in the finding that $10 \%$ of the patients had a left ventricle that was not hypertrophied according to mass criteria and $4 \%$ did not reveal any macroscopic sign of LVH (that is, not even concentric remodelling) despite longstanding aortic stenosis. Variables independently associated with minimal or absent LVH were small body size and a shorter time course of the disease. Short-term follow up after aortic valve replacement in about one third of the patients showed that a re-adaptation of LV geometry to the decreased afterload was more likely to be adequate in patients with LVH than in those without.

\section{PATTERNS OF LV ADAPTATION TO AORTIC} STENOSIS

The main adaptation of the LV myocardium to the pressure overload caused by aortic stenosis is hypertrophy. The purpose of this adaptation is to normalise LV wall stress (by an increase in LV wall thickness) and to maintain systolic function. ${ }^{19}$ However, a wide range of different patterns of LV adaptation to aortic stenosis is possible, ranging from an excessive adaptive response with eccentric hypertrophy ${ }^{6}$ to a response where there is not even an increase in relative $\mathrm{LV}$ wall thickness. This variability may be artificial, because it has been shown that the prevalence of absent LVH in severe aortic stenosis varies between $4 \%$ and $44 \%$ depending on the criteria used to define LVH. ${ }^{20}$ We used a very restrictive definition of LVH in the present study in an attempt to minimise the influence of such a definition bias on the results of our study.

Studies in children with congenital aortic stenosis have shown hypercontractile, thickwalled left ventricles, indicating a mechanism of $\mathrm{LV}$ adaptation to pressure overload without systolic dysfunction that is different from that in adults. ${ }^{21}$ In the present study, the association found in the group with LV concentric remodelling between small body size and absent LVH according to mass criteria probably suggests that in small adults myocardial adaptation to severe aortic stenosis is similar to that in children. In part, this may be due to a below average heart size at the onset of the increased afterload. This never exceeded the 97th percentile of the normal spectrum of LV mass index. ${ }^{13}$ Unlike other studies, ${ }^{4}$ we could not find a direct relation between small hypercontractile, concentrically remodelled ventricles and the female gender. Body size independent of sex was associated with the presence or absence of LVH according to mass.

A surprising finding of our study, and to our knowledge one that has not previously been described, is that $4 \%$ of patients with severe, longstanding aortic stenosis did not show any macroscopic LV adaptation to the increased afterload (no LVH according to mass criteria nor LV concentric remodelling). The fact that the interval since the diagnosis of aortic stenosis predicted this unique adaptive feature is qualitatively not unexpected. However, the mean interval of 3.2 years suggests that other factors must be related to the macroscopically absent adaptive response to the increased afterload.

In addition to body surface area, body mass index (BMI) was also related to $\mathrm{LV}$ adaptation in aortic stenosis in the present study. Previously, it has been suggested that a large body mass index is an independent predictor of the development of excessive $\mathrm{LVH}$ in the presence of normal afterload. ${ }^{22}$ In patients in the present study with excessive LVH and depressed systolic function (18\% of group 1 $\left(B M I=29 \cdot 5 \mathrm{~kg} / \mathrm{m}^{2}\right) v$ the rest of the study population $\left.\left(\mathrm{BMI}=23.8 \mathrm{~kg} / \mathrm{m}^{2}\right), \mathrm{P}=0.01\right)$, the presence of overweight presumably represented volume overload as well as the pressure overload caused by severe aortic stenosis. Because no patients without LVH were obese their left ventricles were not exposed to the additional volume overload caused by increased body weight.

SHORT-TERM FOLLOW UP AFTER AORTIC VALVE REPLACEMENT

Does the more adequate re-adjustment of LV geometry to the postoperative afterload reduction in patients with LVH influence outcome? Possibly it merely reflects the absence of an initial adjustment to the preoperatively increased afterload. In our study, there is no explanation why the postoperative deaths that occurred exclusively among patients with increased relative LV wall thickness irrespective of LV mass were causally related to the adequacy of LV geometric adaptation. However, our findings accord with those of Orsinelli and coworkers ${ }^{7}$ and Aurigemma et $a l^{8}$ who both reported increased postoperative mortality in patients with increased relative $\mathrm{LV}$ wall thickness.

\section{LIMITATIONS OF THE STUDY}

Because this is a retrospective study the clinical data may be incomplete. An important factor was our inability to define accurately the duration of aortic stenosis. Therefore, the precise significance of this variable on the results of this study can only be estimated. Data on postoperative mortality in this study are insufficient to draw any firm conclusions because the follow up period is clearly too short and the absolute number of patients studies is too low for statistical analysis. 


\section{CONCLUSIONS}

One tenth of patients with severe aortic stenosis did not develop LVH according to mass criteria; and $4 \%$ of the patients showed no macroscopic signs of myocardial adaptation to the pressure overload despite a long-term course. Small body size was independently associated with absent LVH according to mass criteria. Ventricular adaptation shortly after aortic valve replacement was more likely to be adequate in patients with LVH than in those without.

1 Sasayama S, Ross J, Franklin D, Bloor CM, Bishop S, Dilley RB. Adaptations of the left ventricle to chronic pressure overload. Circ Res 1976;38:172-8.

2 Levy D, Garrison RJ, Savage DD, Kannel WB, Castelli WP. Prognostic implications of echocardiographically
W. WP. Prognostic implications of echocardiographically determined left ventricular mass in the
heart study. N Engl $₹$ Med 1990;322:1561-6.

3 Iung B, Michel PL, Belkhiria N, Kevorkian JP, Cormier B, Vahanian A, et al. Aortic stenosis without left ventricula hypertrophy (abstract). Eur Heart $\mathcal{F}$ 1992;14 suppl:2370.

Carroll JD, Carroll EP, Feldman T, Ward DM, Lang RM, McGaughey D, et al. Sex-associated differences in left ventricular function in aortic stenosis of the elderly. Circulation 1992;86:1099-107.

5 Ventura HO, Costanzo MR, Tenorio CA, Lavie CJ, Smart $\mathrm{FW}$, Aristizabal DA, et al. Is left ventricular concentric remodeling a predictor of left ventricular hypertrophy in cardiac transplant recipients (abstract)? $₹ \mathrm{Am}$ Coll Cardiol 1994;23:21A.

6 Craver JM, Weintraub WS, Jones EL, Guyton RA, Hatcher CR. Predictors of mortality, complications, and length of stay in aortic valve replacement for aortic stenosis. Circulation 1988;78:85-91.

7 Orsinelli DA, Aurigemma GP, Battista S, Krendel $S$, Gaasch $W H$. Left ventricular hypertrophy and mortality after aortic valve replacement for aortic stenosis. A high risk subgroup identified by properative relative high thickness. $\mathcal{F}$ Am Coll Cardiol 1993;22:1679-83.

8 Aurigemma G, Battista S, Orsinelli D, Sweeney AM, Pape $\mathrm{L}$, Cuenod $\mathrm{H}$. Abnormal left ventricular intracavitary flow acceleration in patients undergoing aortic valve replacement for aortic stenosis: a marker for high post- operative morbidity and mortality. Circulation 1992;86: 926-36.

9 Fujii M, Nuno DW, Lamping KG, Dellsperger KC, Eastham CL, Harrison DG. Effect of hypertension and hypertrophy on coronary microvascular pressure. Circ Res 1992;71:120-6.

10 Feigenbaum H. Echocardiography. 5th ed. Philadelphia: Lea and Febiger, 1994:57-73.

11 Sahn DD, DeMaria A, Kisslo J, Weyman A, Committee on $M$-mode standardization of the American society of echocardiography. Recommendations regarding quantification in M-mode echocardiography: results of a survey of echocardiograpic measurements. Circulation 1978;58: 1072-83.

12 Troy BL, Pombo J, Rackley CE. Measurement of left venricular wall thickness and mass by echocardiography. Circulation 1972;45:602-11.

13 Savage DD, Garrison RJ, Kannel WB, Levy D, Anderson SJ, Stokes III J, et al. The spectrum of left ventricular hypertrophy in a general population sample: the Framingham study. Circulation 1987;75 suppl I:I-26-I33.

14 Rackley CE, Dear HD, Baxley WA, Jones WB, Dodge HT Left ventricular chamber volume, mass, and function in severe coronary artery disease. Circulation 1970;41: 605-13.

15 Devereux RB, Reichek N. Echocardiographic determination of left ventricular mass in man. Circulation 1976 55:613-8.

16 Devereux RB, Alonso DR, Lutas EM, Gottlieb GJ, Campo E, Sachs I, et al. Echocardiographic assessment of left ventricular hypertrophy: comparison to necropsy findings. Am 7 Cardiol 1986;57:450-8.

17 Reichek N, Devereux RB. Left ventricular hypertrophy: relationship of anatomic, echocardiographic and electrocardiographic findings. Circulation 1981;63:1391-8.

18 Reichek N, Devereux RB. Reliable estimation of peak left ventricular systolic pressure by M-mode echographicdetermined end-diastolic relative wall thickness: identification of severe valvular aortic stenosis in adult patients. Am Heart f 1982;103:202-9.

19 Gaasch WH. Left ventricular radius to wall thickness ratio. Am f Cardiol 1979;43:1189-94.

20 Seiler C, Ritter M, Widmer V, Jenni R. Schwere, vorwiegende Aortenstenose ohne linksventrikuläre Hypertrophie (LVH): Einfluss der LVH-Definition. Schweiz Med Wochenschr 1995;125:521-30.

21 Donner R, Carabello BA, Blach I, Spann JF. Left ventricular wall stress in compensated aortic stenosis in children. Am $\mathcal{F}$ Cardiol 1983;51:946-51.

22 Katz AM. Cardiomyopathy of overload. A major determi nant of prognosis in congestive heart failure. $N$ Engl $f$ Med 1990;322:100-10. 